\title{
The Project Place
}

pore-size of materials, with special attention to macropores.

2. To establish a critical and comparative appraisal.

3. To assess the various procedures requiring mercury handling and recommend the safest practice.

4. To publish the findings as an IUPAC Technical Report so it may be broadly disseminated in the corresponding scientific and technical communities. This will be accomplished with help from the equipment manufacturers who will be associated with the project.

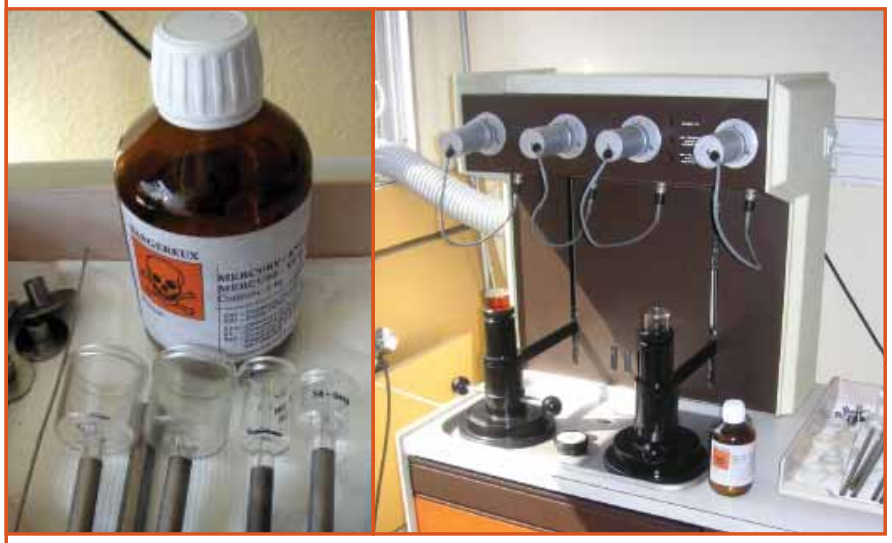

Intruding mercury up to $400 \mathrm{MPa}$ allows for the determination of pore width, from $3 \mathrm{~nm}$ to $100 \mu \mathrm{m}$, in rigid porous materials. The glass intrusion chamber (four different sample sizes are shown here) is to be filled with the sample and then with mercury before being inserted in the high pressure unit (here accommodating two chambers). After each experiment, the mercury spoiled with powder and oil (used to exert the pressure) needs to be cleaned and distilled.

The aim of this project is to provide a first step toward satisfactory answers, by listing, examining, and evaluating all trials conducted in the field. It will consider the intrusion of safer liquids (other molten metals, water, organics) and also the extension of the analysis of capillary condensation data up to the macropore range, which until recently was considered inapplicable. The need for improvements and/or alternative methods is urgent. By clarifying the situation, this project should help in the selection and development of more promising approaches. The issue concerns most scientists and industrialists working with porous materials, including catalysts, phar- maceuticals, building materials, stones of ancient monuments to be restored or protected, adsorbents for chromatography, and liquid purification or gas separation.

For more information contact Task Group Chairman Jean Rouquerol <jean. rouquerol@up.univ-mrs.fr>.

www.iupac.org/projects/2006/2006-021-2-100.html

\section{Priority Claims for the Discovery of Elements with Atomic Number Greater than 111}

\section{by John Corish}

Despite the fact that there are now 111 elements in the Periodic Table, the discovery and naming of a new member of this exclusive group is still seen as one of the most exciting events in the world of chemistry and indeed of science. The making of a new element requires very large and expensive facilities as well as expertise that now often involves international collaborative efforts. The two most recently named elements were made first at Gesellschaft für Schwerionenforschung (GSI) in Darmstadt, Germany. The additions of darmstadtium (110) and roentgenium (111) to the Periodic Table were formally approved by IUPAC in 2003 and 2004, respectively.

The process leading to the naming of a new element is the responsibility of the Inorganic Chemistry Division of IUPAC and is two fold. First, claims for its discovery are thoroughly examined by a Joint Working Party of experts appointed by the presidents of IUPAC and the International Union of Pure and Applied Physics (IUPAP). These experts examine claims submitted by laboratories to determine whether they fully meet the carefully laid-down criteria for the discovery of a new element [Pure Appl. Chem. 63(6), 879-886, 1991]. If the working party is satisfied that the criteria are met, then priority for discovery is assigned to the laboratory that submitted the claims. The second part of the process, in which the successful laboratory is invited to propose a name for the element, can then begin. New names are expected to fall within established guidelines [Pure Appl. Chem. 74(5), 787-791 (2002)] and are carefully examined by IUPAC experts and published for a period for public review, before 